\title{
Meta
}

Journal des traducteurs

Translators' Journal

\section{LAFARGA, Francisco y PegenAute Luis, eds. (2013): Diccionario histórico de la traducción en Hispanoamérica. Madrid/Fráncfort: Iberoamericana/Vervuert, 515 p.}

\section{Rocío García Jiménez}

Volume 61, numéro 3, décembre 2016

URI : https://id.erudit.org/iderudit/1039228ar

DOI : https://doi.org/10.7202/1039228ar

Aller au sommaire du numéro

Éditeur(s)

Les Presses de l’Université de Montréal

ISSN

0026-0452 (imprimé)

1492-1421 (numérique)

Découvrir la revue

Citer ce compte rendu

García Jiménez, R. (2016). Compte rendu de [LAFARGA, Francisco y Pegenaute

Luis, eds. (2013): Diccionario histórico de la traducción en Hispanoamérica.

Madrid/Fráncfort: Iberoamericana/Vervuert, 515 p.] Meta, 61(3), 728-729.

https://doi.org/10.7202/1039228ar d'utilisation que vous pouvez consulter en ligne. 
rôle important dans la façon dont la transmission de l'idée du héros est émise et reçue.

Quant aux théories féministes et la traduction, les articles «The Revolution Cannot Be Translated: Transfiguring Discourses of Women's Liberation in 1970-1980s Japan» écrit par James Welker et «Catherine MacKinnon in Japanese: Toward a Radical Feminist Theory of Translation» de Caroline Norma explorent la traduction en tant qu'activité nécessitant dialogue et interaction (ix). Les deux études considèrent les traductions de textes féministes à différents moments de l'histoire du Japon et à quel point ces traductions (choix des textes traduits, présentations d'idées, adaptation de la terminologie) ont été des enjeux importants dans l'appropriation qui en a été faite par les mouvements féministes nippons.

En ce qui concerne les mouvements queer, le sixième texte, "Translating Queer in Japan: Affective Identification and Translation in the 'Gay Boom' of the 1990s» de Jeffrey Angles, aborde les liens de communauté et de solidarité tissés (dans le cas de son article dans les années 1980 et 1990) entre les lecteurs de textes du mouvement, en japonais et en anglais, ainsi qu'entre les membres de la communauté de traducteurs qui se chargeaient des textes en question et qui permettaient, donc, leur diffusion dans les deux langues.

Dans le même contexte queer, Claire Maree, dans «The Perils of Paisley and Wierd Manwomen: Queer Crossings into Primetime J-TV via Telops », analyse l'évolution de l'onê-kotoba (un style de discours japonais propre à la communauté queer) vers l'usage grand public qui s'en fait dans les émissions de télévision et concrètement dans les textes ou graphiques superposés aux images, très utilisés dans les programmes de variétés japonais.

Et dans le domaine des variations linguistiques, qui sont si présentes et fortes au Japon (voir l'article mentionné ci-dessus sur l'onê-kotoba), «Translating Gendered Voices: From Tanizaki Junichirô's Naomi to Yoshimoto Banana's Kitchen" examine l'onna-kotoba (ou le langage des femmes japonaises) dans sa traduction en anglais. Concrètement, Maree analyse les ouvrages Chijin no ai (1925) de Tanizaki Junichiro et Kitchen (1983) de Yoshimoto Banana, et leurs traductions respectives de 1985 et 1993, afin d'observer comment les voix féminines sont gérées dans les versions en anglais.

"Hirai Teiichi, the Japanese Translator of Dracula and Literary Shape-shifter», de Masaya Shimokusu étudie les différentes traductions réalisées par Hirai Teiichi de l'œuvre de Bram Stoker. L'étude contrastive des différentes versions permet de suivre l'intégration du personnage de Dracula dans l'imagerie populaire japonaise, l'évolution de sa perception dans la société nippone et com- ment le traducteur décide de le présenter afin de proposer une traduction attrayante pour le public de chaque époque. Elle permet également d'envisager les conséquences des interactions inévitables entre les différentes versions du livre et d'autres expressions et diffusions de l'œuvre au cinéma au fil des années.

Finalement, Yin-Ji Piao propose «Yun Dongju's poetry in Japanese Translation». Ce dernier article du recueil offre une analyse littéraire comparative entre les poèmes Hangul originaux de Yun Dong-ju en coréen et leur traduction en japonais. Yin-Ji Piao utilise lesdits poèmes comme des exemples lui permettant de généraliser certains enjeux essentiels du point de vue de la traduction entre le coréen et le japonais (linguistiques, historiques, politiques, sociologiques).

Multiple Translation Communities in Contemporary Japan collige donc plusieurs travaux interdisciplinaires qui ont comme point commun une vision englobante, non statique de la traduction, qui est étroitement liée aux constantes interactions entre communautés, qu'elles soient au Japon ou ailleurs.

ANNA JoAn CASAdEMONT Télé-université du Québec, Québec, Canada

Lafarga, Francisco y Pegenaute Luis, eds. (2013): Diccionario histórico de la traducción en Hispanoamérica. Madrid/Fráncfort: Iberoamericana/Vervuert, 515 p.

Como ya hicieran con el Diccionario histórico de la traducción en España (Editorial Gredos) en 2009, Francisco Lafarga y Luis Pegenaute dan a conocer con esta nueva obra la historia de la traducción en Hispanoamérica, y lo hacen mediante la estructuración, reelaboración y ampliación de la información original previa disponible. Dicha información, menos voluminosa y más dispersa que otras en lo que respecta al campo de la Historia de la traducción (en concreto, de la traducción española), proviene de todos los trabajos e investigaciones realizados hasta el momento, no solo en España, sino también en Hispanoamérica. Por lo tanto, de este diccionario enciclopédico destaca la excelente labor de coordinación de autores y de recopilación de datos que han llevado a cabo sus dos editores.

El volumen consta de 214 entradas que se centran, principalmente, en la traducción literaria, aunque también se presta atención a otras obras que, aunque no son puramente literarias, sí entran dentro del ámbito de las humanidades.

Según indican los editores en la introducción (p. 9-10), las entradas se han dividido en los siguientes grupos: 
- Entradas generales que hacen referencia a aquellos ámbitos geopolíticos donde se ha ejercido la traducción, como pueden ser, por ejemplo, las modernas repúblicas independientes. Sin embargo, en estas entradas también se incluyen aquellas informaciones relacionadas con la traducción en la época del Virreinato o la actividad traductora de los exiliados republicanos. Un ejemplo de ello es la entrada sobre el Virreinato (traducción de lenguas europeas), firmado por Mercedes Serna (p. 467-475). En dicha entrada se hace especial hincapié al tipo de literatura traducida, europea en este caso, durante este periodo de la historia de Hispanoamérica. De este modo, se encuentran alusiones a las traducciones de las obras del Renacimiento italiano (Petrarca) u otras obras de la cultura clásica. También se presta atención a los traductores, provenientes o emigrantes de diversas partes del Virreinato, que se hicieron cargo de estas obras y a su manera de traducir.

- Entradas, también de tipo general, que tratan la traducción entendida como uno de los vehículos de desarrollo cultural y literario de un país. En dichas entradas se encontrará documentación sobre las literaturas extranjeras predilectas de los diferentes países hispanoamericanos e información sobre la labor de los principales traductores e intermediarios de la traducción, es decir, aquellas figuras que colaboraron en la difusión de traducciones. Un ejemplo de este tipo de entrada es la dedicada a Argentina (a cargo de Graciana Vázquez Villanueva, p. 45-56), donde, a lo largo de 11 páginas, se muestra el recorrido histórico de la traducción en este país y la importancia que esta ha ejercido en el desarrollo literario, social y cultural del mismo. De este modo, se puede observar que la traducción en Argentina ha pasado por diferentes fases, pues comenzó siendo un «gesto político, luego herramienta para la democratización del público lector, finalmente, dinamizadora de la renovación en escritura literatura» (p. 54). También se ofrece información sobre los traductores (y escritores de renombre en su mayoría, en el caso argentino) que incidieron de manera significativa en la realidad literaria y traductora de Argentina, como son José Luis Borges, Victoria Ocampo, Julio Cortázar o José Bianco, entre otros. Además de las obras traducidas (y de los escritos sobre la traducción) que dejaron estos autores, en la presente entrada se descubren los pasos editoriales que se dieron en el ámbito traductor, como es el caso de la revista (luego convertida en editorial) Sur.

- Entradas sobre traductores, quienes constituyen, en palabras de los editores (p. 9) el «elemento nuclear de la investigación histórica del pasado de la traducción». Para ello, se ha elaborado un catálogo en el que se han tenido en cuenta diversos factores, como el prestigio, la relevancia histórica de la tarea traductora o incluso la personalidad del propio traductor, en los casos en que estos también ejercieran como escritores, políticos, etc. Las entradas sobre traductores suelen componerse de una breve biografía, alusiones a las formas y contenidos de la actividad traductora desarrollada, actividad como escritor original (si procede), datos bibliográficos sobre las traducciones, comentario de alguna traducción en particular y fuentes secundarias y bibliográficas. En el caso de Octavio Paz (entrada a cargo de Anthony Stanton, p. 334-338), se pueden encontrar numerosas referencias a su manera de entender y llevar a cabo la traducción y a sus principales obras traducidas. Las entradas sobre los traductores vienen acompañadas, en ocasiones, de críticas adecuadas al traductor o a su actividad traductora. Ejemplo de ello es cuando Stanton (p. 337), a modo de conclusión, considera que «[...] toda la obra poética y ensayística de $\mathrm{Paz}$ es una vasta traducción que recrea, sintetiza e inventa de manera original y absolutamente personal temas, formas y prácticas de distintas tradiciones literarias y de muy diversas cosmovisiones culturales.»

Para finalizar con la estructuración del diccionario, falta mencionar que los contenidos del mismo se pueden consultar en los dos índices de que dispone. Por una parte, está el índice en el que se indican los diversos ámbitos geográficos tratados y que se encuentra al principio del diccionario (justo después de los autores responsables de las entradas); y, por otra, está el índice onomástico, al final del diccionario, de todos los autores traducidos.

El diccionario pone de manifiesto, debido a que la mayor parte de la información que contiene se ha construido en torno a la figura del traductor, el auge que el enfoque sociológico está experimentando dentro de los Estudios de Traducción, donde las personas, y no los textos, son los verdaderos responsables de una traducción.

Rocío GARcía JiméneZ

Universidad de Málaga, Málaga, España

Carvais. Robert, NÈgre, Valérie, Cluzel, JeanSébastien and Hernu-BÉLAud, Juliette, eds. (2015): Traduire l'architecture: Texte et image, un passage vers la création? Paris: Picard, 296 p.

Traduire l'architecture is a selection of significant papers given at a series of workshops initiated in 2009 and continued in 2011 and 2013 at the Conservatoire des arts et métiers and Institut national d'histoire de l'art in Paris. The editors present it as the first collective study of the translation of many of the founding documents of European 